\title{
Wage Posting and Business Cycles
}

\author{
By Giuseppe Moscarini and Fabien Postel-VinaY*
}

The canonical framework of Burdett and Mortensen (1998) derives wage dispersion as the unique equilibrium outcome in a stationary environment with meeting frictions and random search. Firms derive monopsony power from search frictions and commit to wage offers. Workers earn rents: wages are not compressed to the opportunity cost of work, owing to the ability of employed workers to receive additional offers and quit directly from one job into another, without experiencing unemployment.

In previous work (Moscarini and Postel-Vinay 2016), we explored the implications of this job ladder for the aggregate dynamics of unemployment, wages, and the firm size distribution at business cycle frequencies. The model establishes a natural connection between the average wage growth in the economy and the pace of Employer-to-Employer (EE) transitions, through two channels. First, a composition effect: workers typically quit a job when they receive a better offer, hence the faster these transitions the higher the pace of reallocation towards high wages, and the higher average wage growth. Second, a strategic effect: the more opportunities workers have to quit, the more aggressive are their employers with their wage responses, to try and retain them. The first effect benefits only job movers, the second both movers and stayers. Therefore, we expect wage growth to be positively related to the pace of $\mathrm{EE}$ reallocation for all workers, but especially for stayers. We verify this empirically with longitudinal micro data from the Survey of Income and Program Participation (SIPP).

More generally, this successful labor market paradigm severs any direct link between unemployment and wages, and relates wage

\footnotetext{
* Moscarini: Yale University and NBER. Department of Economics, Yale University, PO Box 208268, New Haven CT 06520-8268, giuseppe.moscarini@yale.edu. Postel-Vinay: UCL, IFS and Sciences Po. Department of Economics, University College London, Drayton House, 30 Gordon Street, London WC1H 0AX, UK, f.postel-vinay@ucl.ac.uk. We thank Ryan Michaels for his insightful discussion at the 2016 AEA meetings and Jason Faberman for helpful comments.
}

growth directly to EE reallocation. Any correlation between real (and, with some price stickiness, nominal) wage growth and unemployment, the core of the Phillips curve, is purely spurious. Unemployment is low when the jobfinding rate from unemployment is high. In this wage-posting model with random search, employed workers also benefit from more job opportunities, leading to wage growth through the mechanism described above. We argue that monetary authorities concerned with inflationary wage pressure should pay more attention directly to the EE rate and less to the unemployment rate. The post-Great Recession experience, characterized by full unemployment recovery but anemic recovery in both wages and the $\mathrm{EE}$ rate, is an important case in point.

\section{An equilibrium wage-posting model}

\section{A. The environment}

We work with the heterogeneous firm version of Burdett and Mortensen (1998)'s wage posting model. Time is continuous, and the economy is in steady state. The labor market is populated by a unit mass of workers, who can be either employed or unemployed, and by a unit measure of firms. Workers are risk neutral, infinitely lived, and maximize payoffs discounted at rate $\rho$. Firms operate constant-return technologies with labor as the only input and with productivity scale $\omega p$, where $\omega$ is an aggregate component, common to all firms, and $p$ is a firmspecific component, distributed across firms according to a c.d.f. $\Gamma$ over some positive interval $[\underline{p}, \bar{p}]$, with density $\gamma=\Gamma^{\prime}$. Both $\omega$ and $p$ are assumed constant over time. ${ }^{1}$

A firm can be inactive when its productivity

${ }^{1}$ In Moscarini and Postel-Vinay (2016) we analyze the stochastic dynamics of this model, where the impulse is given by random shocks to $\omega$. While equilibrium can be characterized in that case, the dynamic model is intractable and must be solved numerically. Here, we focus on tractable comparative statics to gain intuition about the complex effects of aggregate productivity shocks on labor market equilibrium. 
is too low to profitably operate (see below), so the unit measure of firms includes all potential producers, active and inactive. We denote the lower support of active firm types by $p_{m} \geq p$ (determined momentarily). The measure of active firms is therefore $\bar{\Gamma}\left(p_{m}\right)=1-\Gamma\left(p_{m}\right){ }^{2}$

The labor market is affected by search frictions in that unemployed workers can only sample job offers at Poisson rate $\lambda_{0}$. While searching, they enjoy a value of leisure $b$. Employed workers earn a wage, lose their job at rate $\delta$, and also sample job offers at rate $\lambda_{1}$. For simplicity, we keep all three rates $\lambda_{0}, \lambda_{1}$ and $\delta$ exogenous in this paper, and will analyze the economy's response to changes in those rates. ${ }^{3}$ We denote by $L(p)$ the equilibrium size of a firm of type $p$, and $N(p)=\int_{p_{m}}^{p} L(x) d \Gamma(x)$ the cumulated measure of employment at firms of productivity at most $p$. Thus, $N(\bar{p})$ is total employment and $u=1-N(\bar{p})$ the unemployment rate.

\section{B. Workers and Firm Behavior}

A firm of type $p$ commits to a constant wage $w(p)$ for the duration of any match, and is subjected to an equal treatment constraint, whereby it must pay the same wage to all of its workers. Letting $F(w)=\int_{p_{m}}^{\bar{p}} I\{w(p) \leq w\} d \Gamma(p) / \bar{\Gamma}\left(p_{m}\right)$, where $I(\cdot)$ is the indicator function, denote the c.d.f. of wages posted by all firms (i.e. $F(\cdot)$ is the distribution from which job searchers draw wages), the value $V(w)$ of working at a firm offering wage $w$ solves:

$$
\begin{aligned}
\rho V(w)=w & +\delta[U-V(w)] \\
& +\lambda_{1} \int_{w}^{+\infty}[V(x)-V(w)] d F(x)
\end{aligned}
$$

where $U$ denotes the value of unemployed search. The worker collects a wage $w$ and, loses her job with flow probability $\delta$ (which yields a capital loss of $V(w)-U$ ), or draws an alternate job offer with chance $\lambda_{1}$ that she accepts if its wage (drawn from $F(\cdot)$ ) exceeds that in her current job, $w .{ }^{4}$ Following a similar logic, the value

\footnotetext{
${ }^{2}$ Throughout this paper, a bar over a cdf is used to denote survival functions.

${ }^{3}$ In Moscarini and Postel-Vinay (2016) we endogenize hiring behavior and have job-contact probabilities determined by a matching function.

${ }^{4}$ What workers care about are job values, rather than wages. Showing that workers optimally accept jobs offering a higher
}

of unemployed search solves:

$$
\rho U=b+\lambda_{0} \int_{R}^{+\infty}[V(x)-U] d F(x)
$$

where $R$ is the unemployed workers' reservation wage, defined by $U=V(R)$. Because no worker will accept a lower wage than $R$, the lower support of the wage distribution equals the greater of $R$ and any institutional minimum wage $w_{\min }$.

A firm posting any wage $w \geq R$ loses workers to unemployment at rate $\delta$, and to other more valuable firms at rate $\lambda_{1} \bar{F}(w)$. Simultaneously, the firm hires a number of new workers equal to:

$h(w)=\frac{\lambda_{0} u}{\bar{\Gamma}\left(p_{m}\right)}+\frac{\lambda_{1}}{\bar{\Gamma}\left(p_{m}\right)} \int_{p_{m}}^{\bar{p}} I\{w(p) \leq w\} d N(p)$

where $\lambda_{0} / \bar{\Gamma}\left(p_{m}\right)$ is an unemployed worker's flow probability of receiving a job offer from that particular firm, $\lambda_{1} / \bar{\Gamma}\left(p_{m}\right)$ is the same for an employed worker, and $\int_{p_{m}}^{\bar{p}} I\{w(p) \leq w\} d N(p)$ is the measure of employed job seekers that would earn less than $w$ by staying where they are. Balancing the flows in and out of that firm's workforce yields the steady-state size of a firm posting wage $w, \mathcal{L}(w)=h(w) /\left[\delta+\lambda_{1} \bar{F}(w)\right]$.

Firms maximize steady-state flow profits: ${ }^{5}$

$$
\pi(p)=\max _{w \geq \max \left\langle R, w_{\min }\right\rangle}(\omega p-w) \mathcal{L}(w) .
$$

This program gives rise to an optimal policy $w(p)$ and implied firm size $L(p)=\mathcal{L}(w(p))$. Standard monotone comparative statics arguments establish that $w(p)$ is increasing in $p$ : more productive firms offer higher wages. As a consequence, the equilibrium offer distribution is such that $F(w(p))=\Gamma(p) / \bar{\Gamma}\left(p_{m}\right)$. This can be shown to imply a wage policy defined by

$$
\text { (2) } \begin{aligned}
w(p) & =-\frac{\pi\left(p_{m}\right)}{L(p)} \\
+\omega & {\left[p-\int_{p_{m}}^{p}\left(\frac{\bar{\Gamma}\left(p_{m}\right)+\frac{\lambda_{1}}{\delta} \bar{\Gamma}(p)}{\bar{\Gamma}\left(p_{m}\right)+\frac{\lambda_{1}}{\delta} \bar{\Gamma}(x)}\right)^{2} d x\right] }
\end{aligned}
$$

wage than what they currently earn requires the small step that consists of checking that $V(w)$ is increasing in $w$.

${ }^{5}$ Maximization of steady-state profit flows coincides with full dynamic maximization of the PDV of future profits when firms are infinitely patient. If not, the two problems yield solutions that produce the same steady-state allocation. 
where $\pi\left(p_{m}\right)=L\left(p_{m}\right)\left(\omega p_{m}-w\left(p_{m}\right)\right)$ is the profit earned by the least productive active firm. This marginal firm's type is either $p$ (the least productive type in existence), or the type that achieves zero profit given the lower support of the wage distribution, i.e. $R / \omega$ or $w_{\min } / \omega$, whichever is larger. The marginal firm's profit $\pi\left(p_{m}\right)$ is therefore zero unless neither the reservation wage $R$ nor the statutory minimum wage bind, in which case the least productive firm is active: $p_{m}=p$. Intuitively, the firm's mark-up comprises two terms: the integral in (2) captures market power due to frictions, while the other term compensates the firm for the minimum rent it can earn in the market, $\pi\left(p_{m}\right) \geq 0$.

In what follows, we focus on cases with an active entry margin, i.e. where $\pi\left(p_{m}\right)=0$ and $p_{m}=\max \left\langle R / \omega, w_{\min } / \omega\right\rangle$. The wage function is then given by (2) with $\pi\left(p_{m}\right)=0$ and $R$ defined by $V(R)=U$. The latter implies:

$$
R=b+\left(\lambda_{0}-\lambda_{1}\right) \int_{R}^{+\infty} \frac{\bar{F}(x)}{\rho+\delta+\lambda_{1} \bar{F}(x)} d x
$$

\section{Comparative statics}

We now investigate the comparative response of wages to changes in aggregate productivity $\omega$. Wages depend on $\omega$ directly, and also through the measure of active firms, $\bar{\Gamma}\left(p_{m}\right)$. Moreover, even though contact rates are exogenous in this model, we further consider the possibility that $\omega$ directly impacts firms' labor demand, therefore affecting the job contact rates $\lambda_{0}$ and $\lambda_{1}$. We can then decompose the response as follows:

$$
\begin{aligned}
\frac{d w(p)}{d \omega}=\underbrace{\frac{\partial w(p)}{\partial \omega}}_{\begin{array}{c}
\text { Opportunity } \\
\text { Cost }
\end{array}}+\underbrace{\frac{\partial w(p)}{\partial p_{m}} \frac{d p_{m}}{d \omega}}_{\text {Entry/Exit }} \\
+\underbrace{\frac{\partial w(p)}{\partial \lambda_{0} \frac{d \lambda_{0}}{d \omega}+\frac{\partial w(p)}{\partial \lambda_{1}} \frac{d \lambda_{1}}{d \omega}}}_{\text {Competition }}
\end{aligned}
$$

We study the three pieces of $d w(p) / d \omega$ in turn.

The first Opportunity Cost effect is the direct impact of the productivity scale $\omega$, which reflects the higher opportunity cost (due to a loss of output) of not hiring/retaining workers that a firm pays when $\omega$ increases. Suppose all firms keep their wage offers fixed as $\omega$ rises to $\omega^{\prime}>\omega$. Then firm $p$ will go from productivity $\omega p$ to $\omega^{\prime} p$. Given the arrival rates and strategy of other firms, this firm will optimize by mimicking firm $p^{\prime}=p \omega^{\prime} / \omega$ : whether the firm is more productive for idiosyncratic or aggregate reasons is immaterial to its choice, given a wage offer distribution and arrival rates. So firm $p$ will raise its wage offer to $w\left(p^{\prime}\right)>w(p)$, and, in equilibrium, all firms will raise their wages.

Inspection of (2) when $\pi\left(p_{m}\right)=0$ reveals that the elasticity of the wage function with respect to aggregate productivity $\omega$ is one in this model, so that, if this direct effect were the only one at play, all wages would rise proportionally to $\omega .{ }^{6}$

The second Entry and Exit effect is the impact of aggregate productivity on the set of active firms. The model allows for entry and exit "at the bottom": as $\omega$ changes, so will the entry threshold $p_{m}$. In general, an increase in $\omega$ pulls some relatively unproductive firms into the market, thus lowering wages: $d p_{m} / d \omega<0$ and $\partial w(p) / \partial p_{m}>0$.

The (positive) response of wages to $p_{m}$ is exactly one-for-one at the bottom and changes along the productivity scale in a complex way that depends on $\Gamma(\cdot)$. The negative response of $p_{m}$ to $\omega$ depends on whether the reservation wage $R$ or the minimum wage is binding. In the latter case, $p_{m}=w_{\min } / \omega$ so that $d p_{m} / d \omega$ is simply equal to $-p_{m} / \omega$ (negative unit elasticity). Things are more complex when $R$ is binding, as then $p_{m}=R / \omega$ is defined implicitly by (3) and $d p_{m} / d \omega$ depends, inter alia, on the responses to $\omega$ of the job contact rates $\lambda_{0}$ and $\lambda_{1}$.

The third Competition effect is the direct impact of aggregate productivity on wage competition through the response of the arrival rates of offers $\lambda_{0}$ and $\lambda_{1}$, given the set of active firms. Here we can make the following key remark: given the reservation wage $R$ (or given a binding minimum wage), the wage function (2) only depends on $\lambda_{1}$, and not on $\lambda_{0}$, i.e.:

$$
\frac{\partial w(p)}{\partial \lambda_{0}}=0 \quad \text { and } \quad \frac{\partial w(p)}{\partial \lambda_{1}} \geq 0
$$

This implies that a change in the arrival rate $\lambda_{0}$ of offers to the unemployed has no direct effect on equilibrium wages, and will work only through the reservation wage $R$, whenever it is

\footnotetext{
${ }^{6}$ In Moscarini and Postel-Vinay (2016) we show that, with endogenous hiring, this direct effect is dampened by hiring costs, so that the $w(p)$ with respect to $\omega$ can be less than one.
} 
binding. What matters for wage competition above $R$ is the arrival rate of offers to employed workers $\lambda_{1}$, which is the true index of competition. If $R$ is fixed, or if a binding minimum wage makes it irrelevant, firm commitment insulates wages from cyclical fluctuations in the value of unemployed search, as in Hall and Milgrom (2008)'s credible bargaining, but for very different reasons.

\section{Empirical Evidence}

In Moscarini and Postel-Vinay (2016) we analyze the quantitative bite of each of the effects highlighted above using a fully stochastic dynamic version of the steady-state model presented here, including endogenous and costly hiring by firms. Here, we focus on one important prediction of the model, namely that when the minimum wage binds, the unemployment exit rate does not have any impact on wages, only the job-finding rate from employment does.

Suggestive evidence is provided by Faberman and Justiniano (2015), who notice that the aggregate Employment Cost Index (ECI) is strongly correlated over the business cycle with the aggregate job-switching rate (the fraction of employed workers who change employers without going through unemployment - a proxy for $\lambda_{1}$ in our model). In this paper, we investigate the data further on this question.

Table 1 shows results from regressions of the quarterly growth rate of the ECI on the (quarterly averages of the) job finding rate of the unemployed (UE rate, the empirical counterpart of the model's $\lambda_{0}$ ) and employment-toemployment job switching rate (EE rate). The latter two variables were constructed by Fallick and Fleischman (2004) from the Current Population Survey (CPS), and are now available from 1994 onwards. ${ }^{7}$ We first comment on the first two columns of Table 1, where we use the current release of the ECI as the dependent variable. ${ }^{8}$ In the first column we regress the ECI

\footnotetext{
${ }^{7}$ We include the quarterly change in the unemployment rate as an additional control (omitted in the tables) to capture the $O p$ portunity Cost and Entry/Exit effects of $\omega-$ see equation (4). All of our results are robust to omitting the change in unemployment which, interestingly, is not estimated to have a statistically significant effect on wage growth in any of the regressions.

${ }^{8}$ The current release of the ECI (Bureau of Labor Statistics 2001-2015) covers 2001Q1-2015Q3. Historical series starting in 1980 are also available: we use those in columns 3 and 4 of Table
}

growth rate on the UE rate alone, and obtain, as expected, a positive and significant correlation. Yet in the second column, we include the $\mathrm{EE}$ rate as an additional regressor, and see that, not only is the coefficient on the EE rate positive and significant (as most theories would predict), but also that the effect of the UE rate all but disappears and loses its statistical significance.

We repeat the exercise in columns 3 and 4 of Table 1, using the longer historical ECI series which extends our data set to 1994-present. Although the results are less clear-cut over this longer horizon, we still find that the impact of the UE rate is halved when the EE rate is included into the regression, while the latter has a sizable and significant impact on wage growth.

We conservatively conclude that the aggregate data provide some support to (at least do not disprove) the model's prediction that only $\lambda_{1}$ puts substantial pressure on wage growth. Yet it is questionable whether the relatively short time series that are available are enough to disentangle the effects of the UE and EE rates on wage growth. We thus complement our aggregate evidence with a brief analysis of micro data. One extra advantage of individual-level data is that they allow us to separately estimate the effects of UE and EE rates on the wage growth of job movers and job stayers. The model predicts that neither should be influenced by the UE rate, and both should be influenced positively (although with different magnitudes) by the EE rate.

We extract a panel of workers aged 20-60 from the last four panels (covering 1996-2015) of the SIPP. One advantage of the SIPP is that it allows us to measure job spells fairly precisely: in particular, we can identify job-to-job switchers and job stayers. A significant drawback of the SIPP is that the wage data are very noisy, particularly in earlier panels. Bearing that in mind, we regress individual monthly wage growth on backward-looking six-month moving averages of the aggregate UE and EE rates from Fallick and Fleischman (2004), either on their own or interacted with job stayer/switcher indicators, plus a set of controls. ${ }^{9}$

\footnotetext{
1. We thank Ryan Michaels for mentioning those series to us.

${ }^{9}$ We define a job stayer as someone staying with the same employer in two consecutive months. We attempt to capture "voluntary" job switchers by defining those as people changing employers with less than 29 days' unemployment in between jobs, excluding transitions by dual job holders caused by the loss
} 
TABLE 1-The CYCliCALITy OF EMPLOYMENT COST INDEX GROWTH

Dependent variable: ECI growth

\begin{tabular}{ccccc}
\hline & current (2001Q1-2015Q3) & \multicolumn{2}{c}{ historical (1994Q4-2015Q3) } \\
\hline UE rate & $0.203^{* * *}$ & -0.042 & $0.176^{* * *}$ & $0.096^{* *}$ \\
EE rate & - & $0.293^{* * *}$ & - & $0.084^{* *}$ \\
\hline
\end{tabular}

Note: Quarterly data, MA-smoothed. All rates are normalized for comparability.

Source: CPS compiled by Fallick and Fleischman (2004), BLS, and authors' calculations.

TABLE 2-THE CYCLICALITY OF WAGE GROWTH.

Dependent variable: monthly log wage growth

\begin{tabular}{lcccc}
\hline UE rate & $0.266^{* * *}$ & -0.165 & - & - \\
EE rate & - & $0.515^{* * *}$ & - & - \\
(UE rate)*switcher & - & - & $0.583^{* * *}$ & -0.355 \\
(UE rate)*stayer & - & - & $0.345^{* * *}$ & -0.119 \\
(EE rate)*switcher & - & - & - & $1.032^{*}$ \\
(EE rate)*stayer & - & - & - & $0.591^{* * *}$
\end{tabular}

Note: Monthly data, 1996m1-2013m7 (with gaps). All rates are normalized for comparability. Controls include gender, race, age, marital status, education, industry, occupation, mover/stayer status, and establishment size. Standard errors are clustered by individual. Source: CPS compiled by Fallick and Fleischman (2004), SIPP, and authors' calculations.

Table 2 shows the results, which broadly confirm the aggregate results from Table 1. The first two columns of Table 2 mirror the regressions in Table 1 and show that the positive correlation between the UE rate and wage growth disappears when the EE rate is included as a regressor. Breaking down the effects of the UE and EE rates between job switchers and job stayers (columns 3 and 4) yields similar results for both worker categories, although less precisely estimated for job switchers.

Taken together, those descriptive results support the model's prediction that wages are primarily responsive to the job contact rate of employed workers, rather than to the unemployment exit rate. Beyond the model, and as pointed out before by Faberman and Justiniano (2015), this evidence suggests that the EE job switching rate is a strong predictor of future wage growth and, ultimately, of inflation.

\section{REFERENCES}

Burdett, Kenneth, and Dale T Mortensen. 1998. "Wage Differentials, Employer Size, and Unemployment." International Economic Review, 39(2): 257-73.

of the main job (the second job becoming the main one, creating an apparent employer-to-employer transition). The residual category are thus dual job holders losing their main job.
Bureau of Labor Statistics. 2001-2015. "Employment Cost Index, Civilian Workers, Non Seasonally Adjusted, CIU1010000000000I." United States Department of Labor. http://www.bls.gov/data/ (accessed December 24, 2016).

Faberman, R Jason, and Alejandro Justiniano. 2015. "Job Switching and Wage Growth." Chicago Fed Letter, 337.

Fallick, Bruce, and Charles A Fleischman. 2004. "Employer-to-Employer Flows in the U.S. Labor Market: The Complete Picture of Gross Worker Flows." Board of Governors of the Federal Reserve System Finance and Economics Discussion Series 2004-34.

Hall, Robert E, and Paul R Milgrom. 2008. "The Limited Influence of Unemployment on the Wage Bargain." American Economic Review, 98(4): 1653-74.

Moscarini, Giuseppe, and Fabien PostelVinay. 2016. "Wage Posting and Business Cycles: A Quantitative Exploration." Review of Economic Dynamics, 19(1).

United States Census Bureau. 1996-2015. "Survey of Income and Program Participation." United States Department of Commerce. http://www.census.gov/sipp/ (accessed December 24, 2016). 